This is a peer-reviewed, accepted author manuscript of the following paper: Elsherbiny, K., Tezdogan, T., Kotb, M., Incecik, A., \& Day, S. (2019). An experimental investigation of the trim effect on the behaviour of a containership in shallow water. In ASME 2019 38th International Conference on Ocean, Offshore and Arctic Engineering [OMAE2019-95790] ASME. https://doi.org/10.1115/OMAE2019$\underline{95790}$

\title{
AN EXPERIMENTAL INVESTIGATION OF THE TRIM EFFECT ON THE BEHAVIOUR OF A CONTAINERSHIP IN SHALLOW WATER
}

\author{
Khaled Elsherbiny ${ }^{1}$ \\ University of Strathclyde \\ Glasgow, United Kingdom \\ \& \\ Science, Technology and
Maritime Transport \\ Alexandria, Egypt
}

\author{
Tahsin Tezdogan \\ University of Strathclyde \\ Glasgow, United Kingdom
}

\author{
Mohamed Kotb \\ Arab Academy for Science, \\ Technology and Maritime \\ Transport \\ Alexandria, Egypt
}

\author{
Atilla Incecik \\ University of Strathclyde \\ Glasgow, United Kingdom
}

\author{
Sandy Day \\ University of Strathclyde \\ Glasgow, United Kingdom
}

\section{ABSTRACT}

A new division of the Suez Canal in Egypt, termed the New Suez Canal, was opened for international navigation in August 2015. It is therefore important to ensure the safety of ships navigating this new section of the canal. Measures to avoid grounding and/or drifting to the canal banks are necessary. Additionally, accurate prediction data for ship squat and under keel clearance is crucial.

This paper presents the results of experimental work carried out at the Kelvin Hydrodynamic Laboratory at the University of Strathclyde, Glasgow, to study the effect of trim on containership sailing characteristics in shallow waters using Kriso Container Ship (KCS) model.

A series of model tests were conducted to measure the resistance, sinkage variations with speed, water depth and loading conditions under different trimming angles at 1:75 scale. The objective of this work is to examine the range of ship trim for safe and efficient sailing in restricted water in both depth and width. The study also aimed to provide data to be used in validating numerical computations to be carried on the same type of vessel to detect the best trim angle for ships during sailing in restricted waters to reduce resistance and therefore fuel consumption.
For depth Froude numbers higher than 0.4, the results show that the ship model sinkage is less for aft trim than for level trim or forward trim. Concurrently, it can be observed that there is less water resistance for aft trim than for forward trim, albeit level trim shows the least resistance. The test was conducted for one value of model draft which was $0.144 \mathrm{~m}$. Side bank effect were also examined.

Keywords: Trim optimization, squat and resistance prediction, Experiments, restricted water, New Suez Canal, KCS model

$\begin{array}{cl}\text { NOMENCLATURE } \\ \mathrm{K} & \text { Blockage factor } \\ \mathrm{b} & \text { Ship's breadth } \\ \mathrm{T} & \text { Ship's draft } \\ \mathrm{H} & \text { Depth of the water } \\ \mathrm{B} & \text { Canal's breadth. } \\ \mathrm{LVDT} & \text { Linear Variable Differential Transformer } \\ \mathrm{L}_{1} & \text { LVDT }_{1} \text { vertical displacement } \\ \mathrm{L}_{2} & \text { LVDT }_{2} \text { vertical displacement } \\ \mathrm{U}_{\mathrm{A}} & \text { Random uncertainty }_{\mathrm{S}} \\ \mathrm{S} & \text { standard deviation } \\ \mathrm{k} & \text { Coverage factor }\end{array}$

\footnotetext{
${ }^{1}$ Contact author: khaled.elsherbiny@strath.ac.uk
} khaled.elsherbiny@aast.edu 


\section{$\mathrm{U}_{\mathrm{B}} \quad$ Systematic uncertainty \\ SEE Standard error of estimate \\ SSR Sum of the square of the residuals \\ $\mathrm{N} \quad$ Number of calibration point \\ INTRODUCTION}

The ship behaviour is influenced by the hydrodynamic interaction between the ship hull and seabed in shallow water. Furthermore, if the ship is advancing through a confined channel such as a canal or river, the ship behaviour and performance will highly be influenced due to the flow velocity between the hull's bottom and seabed increases, also between the hull's side and the bank of canal or river. This increases in flow velocity produces greater reduction in pressure around the ship hull, as per Bernoulli's theorem Larsson [1]. As a consequence of this reduction the ship will be compensated by moving vertically to direction of low pressure downwards this is called sinkage and will mostly trim as well due to the asymmetry between the fore and aft part of the ship Lataire [2]. Furthermore, a significant increase in resistance arises due to this hydrodynamic interaction. According to Terziev [3], ships experience a drop in speed when a ship enters a shallow water. A drop in speed may be up to $30 \%$ upon entering shallow waters and may rise up to $60 \%$ if the ship is advancing through a confined channel such as river or a canal.

There are various methods available to predict ship squat and resistance in shallow water. These methods include empirical formulae, analytical, numerical and experimental methods. Empirical formulae can quickly estimate the squat according to the ship dimensions, ship coefficients, ship speed and water depth. These formulae are obtained from a series of model tests, but these formulae still have certain conditions and constraints to be satisfied before they can be applied. The analytical method mainly uses assumptions based on simple potential theory such as slender body theory. The numerical method or Computational Fluid Dynamics (CFD) methods have been more recently developed and can be easily used for predicting a ship's squat. The experimental methods are more accurate to simulate and predict squat phenomena and resistance. In this paper, a series of experimental tests are carried out on a container ship model (KCS) to study ship squat and resistance characteristics while navigating in restricted water.

Factors governing ship squat include ship speed, water depth, block coefficient and blockage factor $(\mathrm{K})$ given by Equation (1).

$$
\mathrm{K}=\frac{\mathrm{b} * \mathrm{~T}}{\mathrm{~B} * \mathrm{H}}
$$

Where $b$ is the ship's breadth, $T$ is the ship's draft, $B$ is the canal's breadth and $\mathrm{H}$ is the depth of the water.

Many researchers have investigated ship squat in restricted water. Constantine [4], studied the different behaviour of ship squat for various ship speeds (subcritical, critical and supercritical) and the ratio of midship section to the cross section of the fairway. Tuck [5], calculated the flow around a slender hull in shallow water and devised formulae to predict the wave resistance, sinkage and trim at subcritical and supercritical speeds. Millward [6], presented an overview on the general problem of a ship in shallow water and developed an expression for maximum bow squat in laterally unrestricted water based on model tests with various ship speeds. Gourlay [7], used a theoretical method based on the linear superposition of slenderbody shallow-water flow solutions to predict the sinkage and trim of two moving ships as they pass each other, either from opposite directions, or one ship overtaking the other. Delefortrie, $G$ [8], investigated the squat when a ship is sailing in a muddy area. Lataire [9], predicted the squat for a wide range of water depths and widths of a canal with rectangular cross section using an experimental method for a model scale KVLCC2. Shivachev [10], investigated influence of trim on KCS ship resistance in deep and calm water using experimental and numerical methods. The study showed the model test and CFD method had good agreement in prediction of total resistance trend with respect to trim. Furthermore, the study confirmed that significant reduction in total resistance are achievable by operating the ship at optimum trim. Sherbaz [11], used a numerical method to assess trim influence of MOERI container ship resistance in deep water. The study showed that trim has pronounced increasing effect on resistance during bow trim. Furthermore, the effect on resistance is varying during stern trim and optimum trim point is $0.02 \mathrm{~m}$ trim by stern.

\section{EXPERIMENTAL SETUP}

This experimental work has been conducted at the Kelvin Hydrodynamics Lab at the University of Strathclyde. The towing tank principle dimensions are shown in

Table 1 and Figure 1a and $\mathrm{b}$. The maximum speed of the carriage is $5 \mathrm{~m} / \mathrm{s}$ which is driven along rails by a computercontrolled digital driven DC motor. The tank is equipped with a wavemaker able to generate regular and irregular waves up to 0.5 $\mathrm{m}$ high. The tank is also fitted with computer controlled unit for variable water depth. The water depth at the tank was set at 0.32 $\mathrm{m}$ for shallow water tests.

Table 1: Main dimensions of the tank

\begin{tabular}{|l|l|}
\hline Total length & $76 \mathrm{~m}$ \\
\hline Width & $4.6 \mathrm{~m}$ \\
\hline Maximum water depth & $2.5 \mathrm{~m}$ \\
\hline
\end{tabular}

(a)

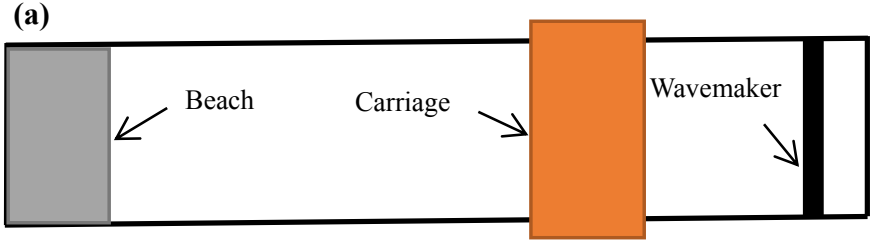


(b)

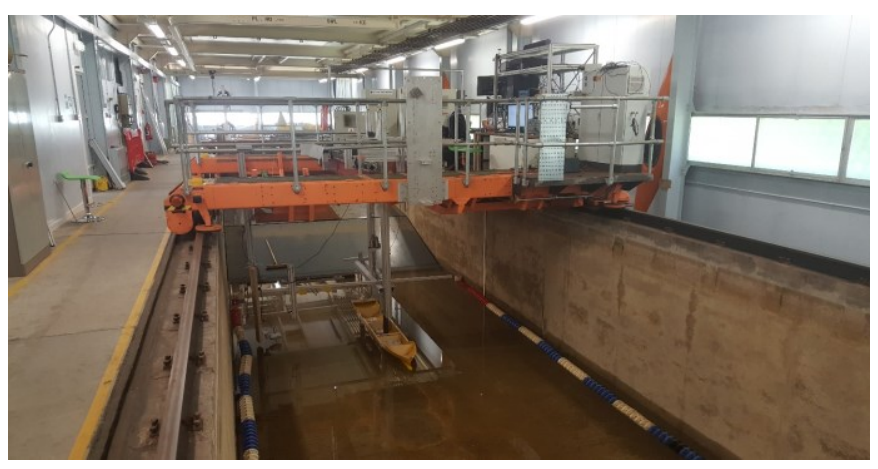

Figure 1: Kelvin hydrodynamic lab: a) is schematic drawing for tank and $b$ ) is real picture during the experiment.

A KCS model was used to experimentally test squat characteristics at different speeds, deep and shallow water (see Figure 2a). Full scale and model scale particulars are given in Table 2

The model tests are carried out at a range of ship speeds and ship drafts. Two LVDTs (Linear Variable Differential Transformer) were employed to measure trim and sinkage. The sinkage $\mathrm{LVDT}_{1}$ was attached at the mid ship point to measure the heave motion in dynamic mode and the trim $\mathrm{LVDT}_{2}$ was attached at the model forepeak, using the configuration as illustrated in Figure $2 \mathrm{~b}$. The trim angle was then calculated according to Equation (2).

$$
\text { Trim }=\tan ^{-1}\left(\frac{L_{2}-L_{1}}{d}\right)
$$

Where $\mathrm{L}_{1}$ and $\mathrm{L}_{2}$ are the $\mathrm{LVDT}_{1}$ and $\mathrm{LVDT}_{2}$ vertical displacement, respectively, and $\mathrm{d}$ is the distance between the two LVDT's (=1105 mm).

A load cell was used to measure the water resistance force. This load cell was attached at the midship point. The model was free to move in the vertical plane (heave and pitch motions) while being restricted in all other directions. One of the main features of the model test in the towing tank is the possibility of extending the results to the full scale, because in this test the Suez Canal cross section and KCS model were constructed with scale factor 75 .

(a)

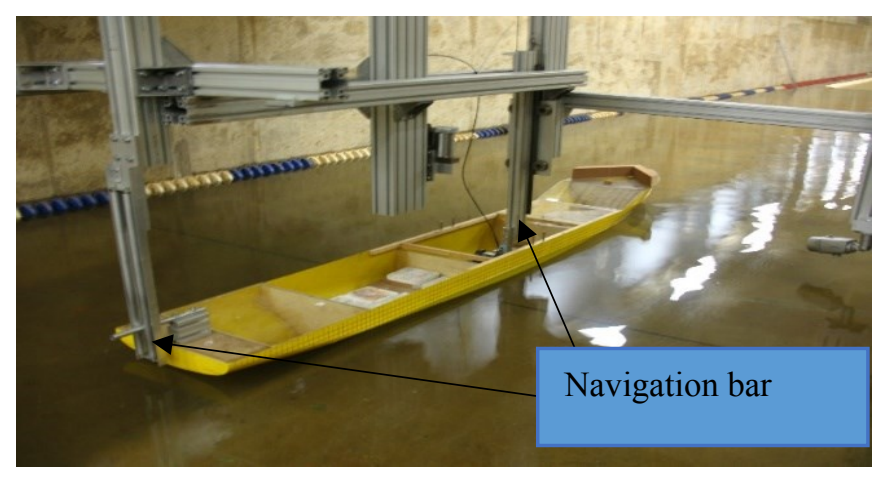

(b)

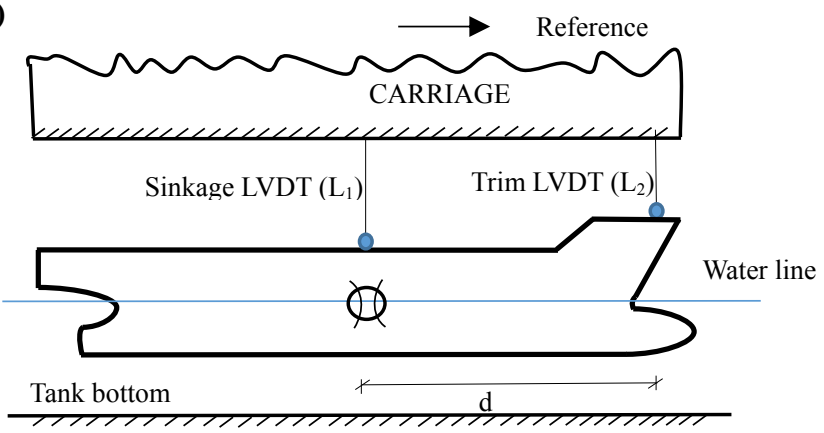

Figure 2: KCS model: a) real model and b) schematic drawing for trim and sinkage measurements using LVDTs

Table 2: KCS main particulars

\begin{tabular}{|c|c|c|}
\hline Parameters & Full scale & Model scale \\
\hline Scale & 1.00 & 75 \\
\hline $\begin{array}{c}\text { Length between } \\
\text { perpendiculars (m) }\end{array}$ & 230 & 3.067 \\
\hline $\begin{array}{c}\text { Length at water line (m) } \\
\text { Breadth at water line (m) }\end{array}$ & 232.5 & 3.1 \\
\hline Depth (m) & 19 & 0.429 \\
\hline Draft (m) & 10.8 & 0.25 \\
\hline $\begin{array}{c}\text { Displacement (m3) } \\
\text { Wetted surface area w/o } \\
\text { rudder (m2) }\end{array}$ & 52030 & 0.123 \\
\hline $\begin{array}{c}\text { Block Coefficient } \\
\text { Midship section area } \\
\text { Coefficient }\end{array}$ & 0.651 & 0.985 \\
\hline $\begin{array}{c}\text { Longitudinal centre of } \\
\text { buoyancy (\%), fwd }+\end{array}$ & -1.48 & -1.48 \\
\hline
\end{tabular}

The towing tank at Kelvin hydrodynamic lab was prepared for three test conditions and different blockage ratio conditions; ach case at various speed. Furthermore various trim angle for Case I.

Case I: Channel banks are introduced through side planks. This configuration is intended to test effects of both water depth and width (blockage effects) (refer to Figure $3 a$ and b). This case also aims to simulate the cross sectional area of the New Suez 
Canal. It was set up at a scale of 1:75 with respect to its real dimensions. (Refer to Table 3)

Case II: Similar to Case I but with reduced water surface width and bottom width. This case was designed for studying higher blockage ratios. (Refer to Figure 4a, b and Table 3)

Case III: The tank cross section is rectangular $(4.6 \mathrm{~m}$ wide and $0.32 \mathrm{~m}$ water depth). This is to simulate water depth effects only on ship sailing characteristics. Channel bank effects are excluded (refer to Figure $5 \mathrm{a}$ and $\mathrm{b}$ ).

(a)

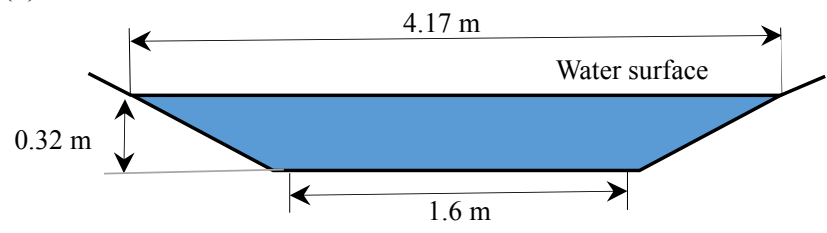

(b)

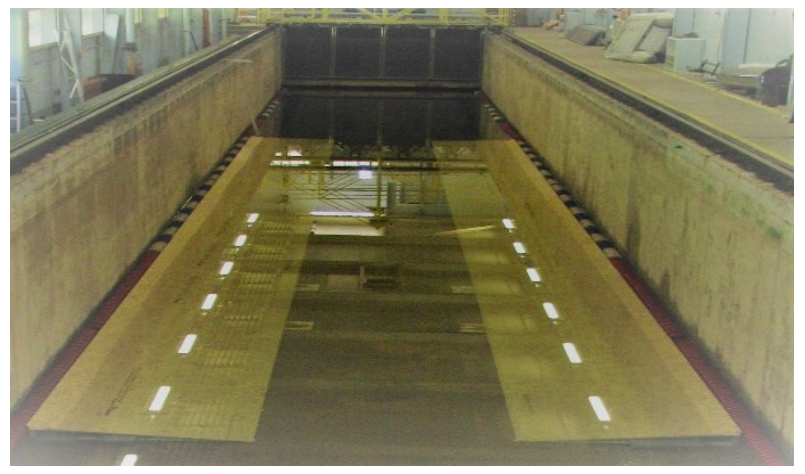

Figure 3: Depictions of the Case I, a) schematic drawing and b) real photo from tank setup

(a)

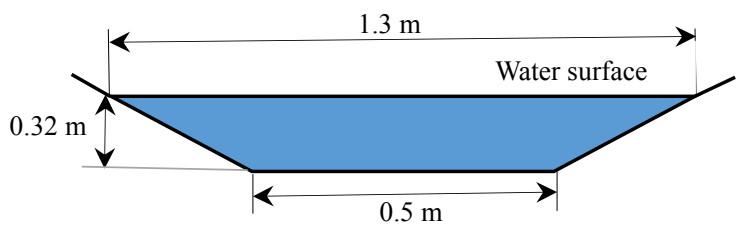

(b)

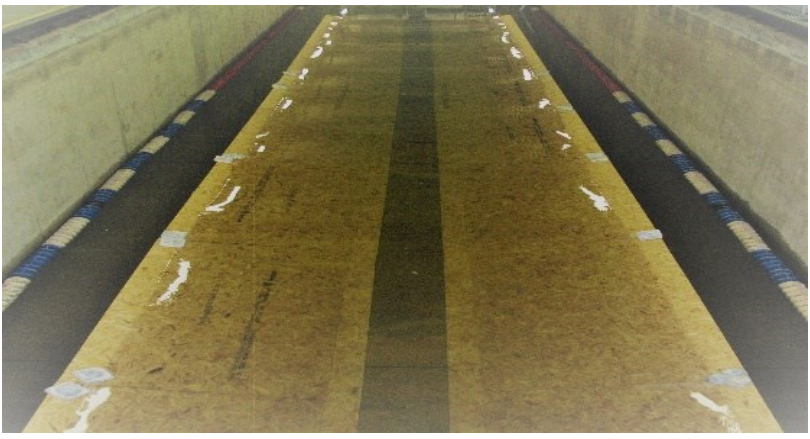

Figure 4: Depictions of the Case 2, a) schematic drawing and b) real photo from tank setup

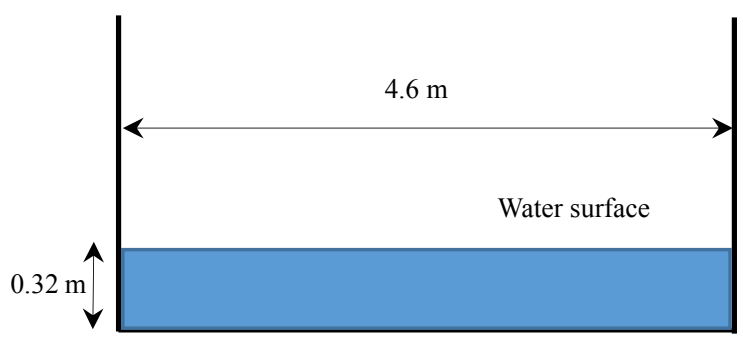

Figure 5: Schematic drawing for depictions of the Case III

Table 3: Blockage effect for Case I, II \& III

\begin{tabular}{|c|c|c|c|c|c|}
\cline { 2 - 6 } \multicolumn{1}{c|}{} & \multicolumn{2}{c|}{ Model } & \multicolumn{2}{c|}{ Tank } & $\begin{array}{c}\text { Blockage raito } \\
(\mathrm{K})\end{array}$ \\
\hline Case & $\mathrm{b}(\mathrm{m})$ & $\mathrm{T}(\mathrm{m})$ & $\overline{\mathrm{B}}(\mathrm{m})$ & $\mathrm{H}(\mathrm{m})$ & $(\mathrm{b} * \mathrm{~T}) /(\overline{\mathrm{B}} * \mathrm{H})$ \\
\hline I & 0.429 & 0.144 & 2.88 & 0.32 & 0.067 \\
\hline II & 0.429 & 0.144 & 0.9 & 0.32 & 0.2145 \\
\hline III & 0.429 & 0.144 & 4.6 & 0.32 & 0.042 \\
\hline
\end{tabular}

All tests in three mentioned cases were performed in fresh water and calm water. The model was only allowed to move in heave and pitch while others motions were restricted. Model resistance, trim, sinkage and actual speed of the model were recorded during the runs.

For draft 0.144 the tests were carried out for various number of trim angles at different model speeds. Selected trim angle range were $0,0.3$ by aft, 0.3 by fwd, 0.9 by aft and 0.9 by fwd.

Free weights inside the model are arranged in such a way to achieve the required trim. This trim is fine tuned using the $\mathrm{LVDT}_{1}$ and $\mathrm{LVDT}_{2}$ with their inputs are fed to the "Spike" software within the tank acquisition system.

\section{UNCERTAINTY ANALYSIS}

Estimation of experimental uncertainty is needed to assess the confidence in the presented results. The uncertainty is divided into two types $\mathrm{A}$ and $\mathrm{B}$, based on the way that the uncertainty is evaluated.

Type A standard uncertainty or termed 'random uncertainty' (ISO GUM) [12], this is a method of determining standard uncertainty by evaluation of a statistical analysis of a series of repeated observations. The experiments was carried out by repeating the test for five times at the same conditions at the velocity of Froude number based on depth $\left(\mathrm{Fn}_{\mathrm{h}}\right)$ equal to 0.57 .

Equation (3) shows how to measure uncertainty using the Type $\mathrm{A}\left(u_{A}\right)$ method: 


$$
\mathrm{u}_{\mathrm{A}}=\sqrt{\frac{\mathrm{S}^{2}}{\mathrm{i}}}
$$

Where $\mathrm{i}$ is the number of repeat observations and $\mathrm{S}$ is the standard deviation of the values.

To obtain a 95\% level of confidence uncertainty, the uncertainty Type $\mathrm{A}\left(\mathrm{u}_{\mathrm{A}}\right)$ is multiplied by a coverage factor $\mathrm{k}$ as in Equation (4).

$$
U_{A}=k u_{A}
$$

Where $\mathrm{k}=1.96$ for a $95 \%$ level of confidence.

Type B standard uncertainty or termed 'systematic uncertainty' (ISO GUM) [12], this is a method of standard uncertainty obtained by means other than statistical analysis, for example instrument calibration data and linear regression analyses. In the present work, three calibration data sets from the LVDT sinkage, LVDT bow and load cells were used to obtain a standard error of estimate (SEE), then multiplied by 3 to obtain a $95 \%$ level of confidence uncertainty as described by 'ITTCuncertainty analysis instrument calibration $2017^{\prime}$ [13].

To calculate Type B with a 95\% level of confidence, Equation (5) was used.

$$
\mathrm{U}_{\mathrm{B}}=\mathrm{SEE} * 3
$$

Where SEE is the standard error of the estimate see equation (6)

$$
\mathrm{SEE}=\sqrt{\frac{\mathrm{SS}_{\mathrm{R}}}{(\mathrm{N}-2)}}
$$

Where SSR is the sum of the square of the residuals and $\mathrm{N}$ is the number of calibration points.

$$
\operatorname{SSR}=\sum_{\mathrm{i}=1}^{\mathrm{N}}\left(\mathrm{y}_{\mathrm{i}}-\mathrm{a}-\mathrm{bx}_{\mathrm{i}}\right)^{2}
$$

Finally, an evaluation of the standard uncertainty, U, was made using Equation (8).

$$
U=\sqrt{U_{A}^{2}+U_{B}^{2}}
$$

In the present experiment the trim was measured and combined between two standard uncertainties which came from LVDT sinkage and LVDT bow so the combined uncertainty analyse were performed for trim measurements.

The combined standard uncertainty is evaluated by the propagation of uncertainty (ISO GUM) [12], and is given by equation (9)

$$
\mathrm{U}_{\text {Ctrim }}^{2}=\left(\frac{\partial \text { Trim }}{\partial \text { LVDTbow }}\right)^{2} * \mathrm{U}_{\text {Bbow }}^{2}+
$$

$$
\left(\frac{\partial \text { Trim }}{\partial \text { LVDTsinkage }}\right)^{2} * \mathrm{U}_{\text {Bsinkage }}^{2}
$$

Where LVDT bow and LVDT sinkage is the values of LVDTS at certain speed.

Table 4: Uncertainty of measurements for total resistance, sinkage and trim

\begin{tabular}{|c|c|c|c|c|}
\hline \multicolumn{5}{|c|}{ Total resistance (RT) } \\
\hline $\mathrm{m} / \mathrm{s}$ & $\mathrm{U}_{\mathrm{A}}(\mathrm{N})$ & $\mathrm{U}_{\mathrm{B}}(\mathrm{N})$ & $\mathrm{U}(\mathrm{N})$ & Percentage \\
\hline 1.426 & 0.21 & 0.0286 & 0.212 & \pm 0.45 \\
\hline \multicolumn{5}{|c|}{ Sinkage } \\
\hline $\mathrm{m} / \mathrm{s}$ & $\mathrm{U}_{\mathrm{A}}(\mathrm{mm})$ & $\mathrm{U}_{\mathrm{B}}(\mathrm{mm})$ & $\mathrm{U}(\mathrm{mm})$ & Percentage \\
\hline 1.426 & 0.428 & 0.572 & 0.714 & \pm 1.86 \\
\hline \multicolumn{5}{|c|}{ Trim } \\
\hline $\mathrm{m} / \mathrm{s}$ & Combined Uncertainty $\mathrm{U}_{\mathrm{C}}(\mathrm{deg})$. & Percentage \\
\hline 1.426 & \multicolumn{4}{|c|}{0.0789} \\
\hline
\end{tabular}

The uncertainty values for total resistance, sinkage and trim at model scale speed $1.426 \mathrm{~m} / \mathrm{s}$ it is shown from above that resistance, sinkage and trim of this model is estimated at \pm 0.45 , \pm 1.86 and \pm 4.92 respectively at $95 \%$ of confidence level.

\section{EXPERIMENTAL RESULTS AND DISCUSSION}

In the present paper, total resistance, sinkage and trim of KCS hullform are measured in depth and width restricted water at different depth Froude number and blockage ratio. In this study one draft of $0.144 \mathrm{~m}$ was investigated for various depth Froude number between 0.1 to 0.67 and five different trim values; ranging from 0 to 0.9 degrees for first case.

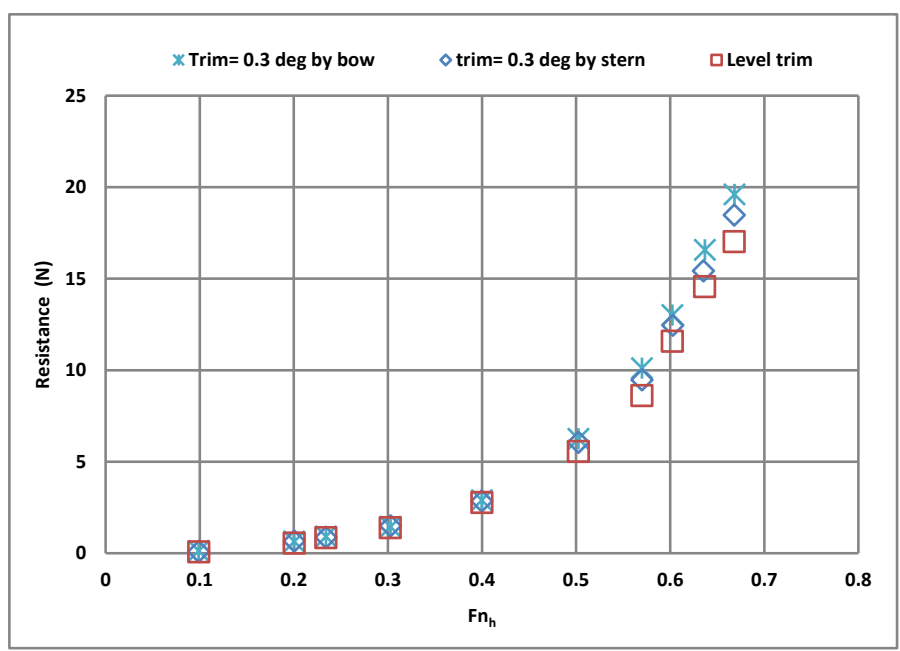

Figure 6: Total resistance comparisons between level trim and \pm 0.3 deg. trim

No significant change in the resistance values experienced by the model as far as trim is concerned up to 0.4 depth Froude 
Number (refer to Figure 6). Past $\mathrm{Fn}_{\mathrm{h}}=0.4$, level trim angle gave the lowest resistance. The test also reveals that resistance is a little higher for the trimmed by bow case than stern trimmed case.

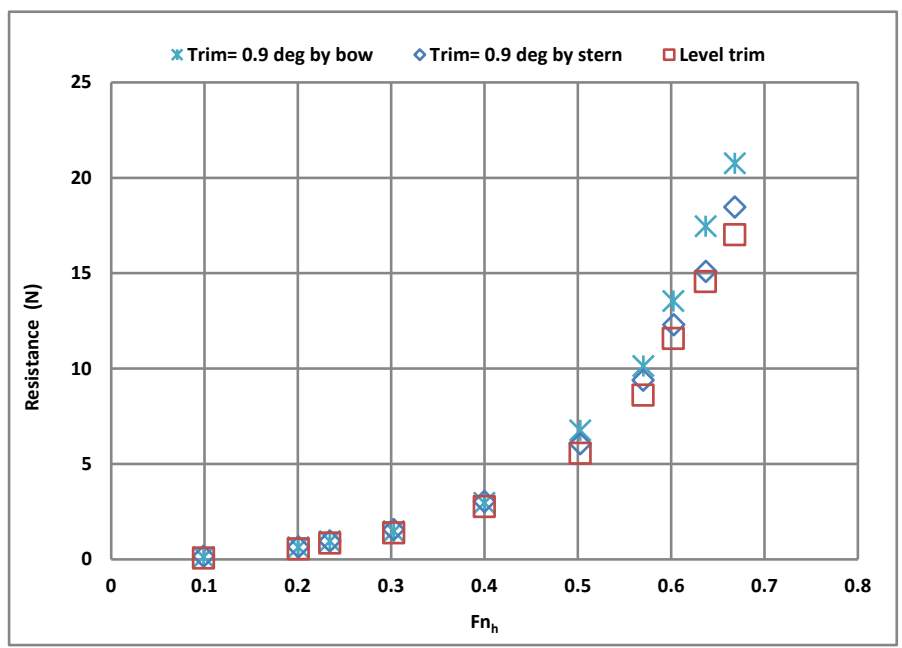

Figure 7: Total resistance comparisons between level trim and \pm 0.9 deg. trim

Figure 7 displays resistance variation with depth Froude numbers for a wider trim range $\left( \pm 0.9^{\circ}\right)$. Similar trend to Figure 6 was observed except for higher resistance due to trim.

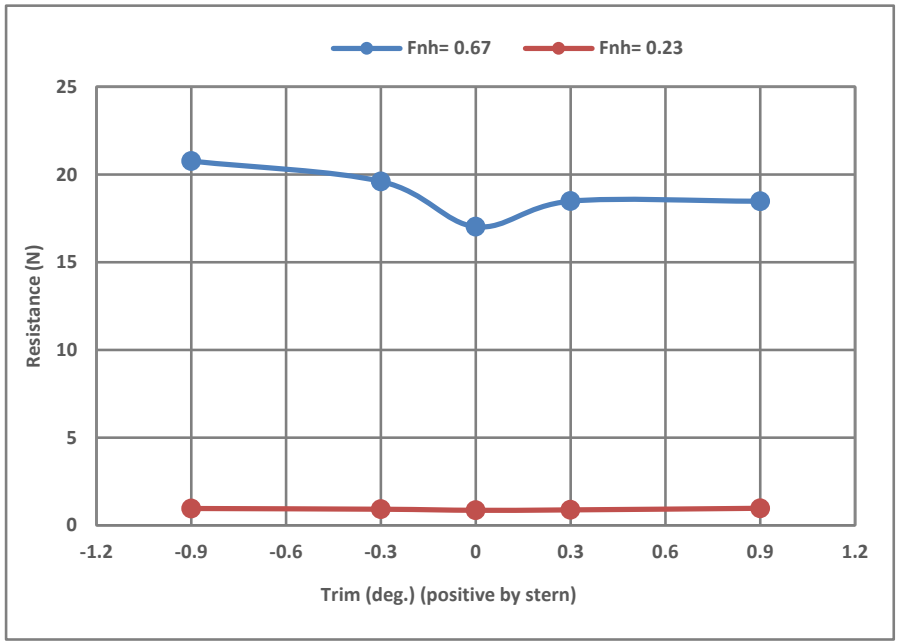

Figure 8: Total resistance for various trim angle at high and low speed.

Figure 8 displays total resistance variations versus positive and negative trim angle at 0.23 and 0.67 depth Froude numbers respectively. It's clear that for the high depth Froude number significant increase in total resistance when model was trimmed by bow by $18 \%$ for 0.9 degree and $13 \%$ for 0.3 degree, compared to level trim condition. In contrast, total resistance increases by $7.88 \%$ for 0.3 degree and $7.86 \%$ for 0.9 degree when model was trimmed by stern. Meanwhile, no variation in resistance with either aft or forward trim at relatively low $\mathrm{Fn}_{\mathrm{h}}$.

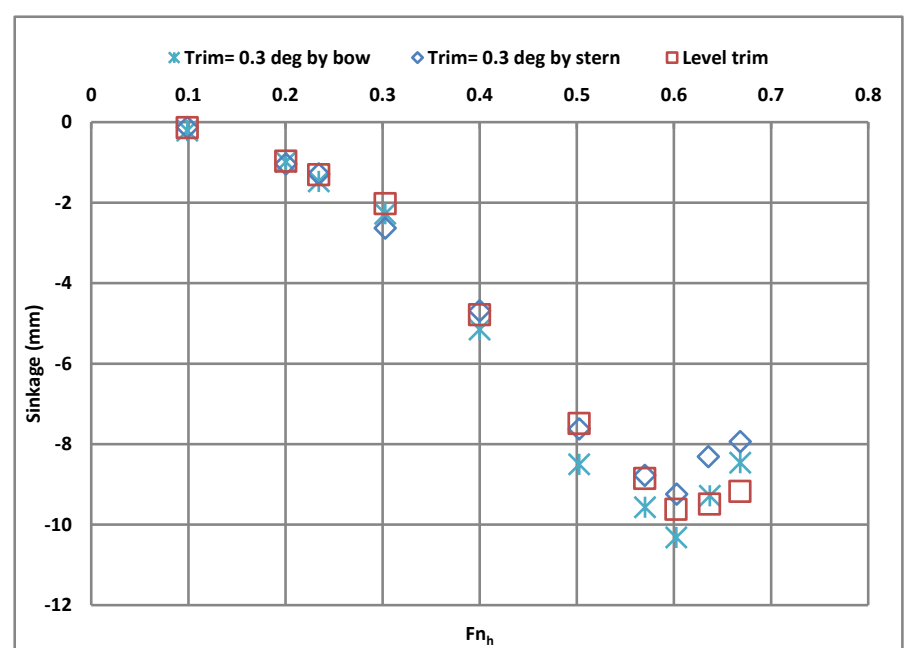

Figure 9: Sinkage comparisons between level trim and $\pm 0.3 \mathrm{deg}$. trim

Negligible change in the sinkage values was observed over the depth Froude Number range up to 0.4 (refer to Figure 10). Trimming by bow exhibits the lowest value of sinkage at about $F n_{h}=0.6$, lower sinkage values are observed past this Froude's number value for the three trim values tested.

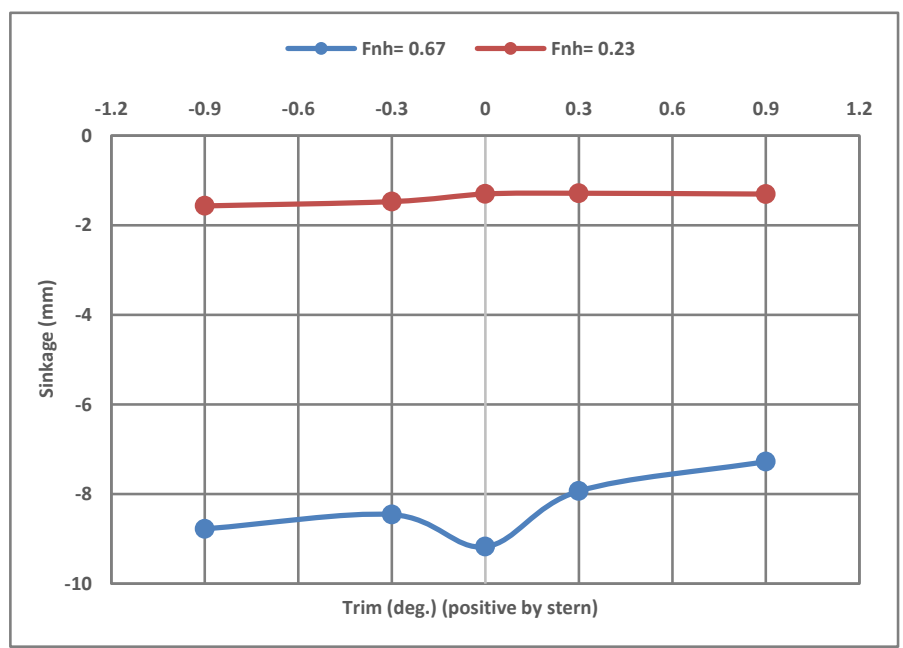

Figure 10: Sinkage comparisons between level trim and $\pm 0.9 \mathrm{deg}$. trim

Figure 10 shows sinkage variation with $\mathrm{Fn}_{\mathrm{h}}$ at 0.9 degree aft and forward trim. It can be observed that, similar to the 0.3 trim by aft and forward behaviour, aft trim case indicated less sinkage values. 


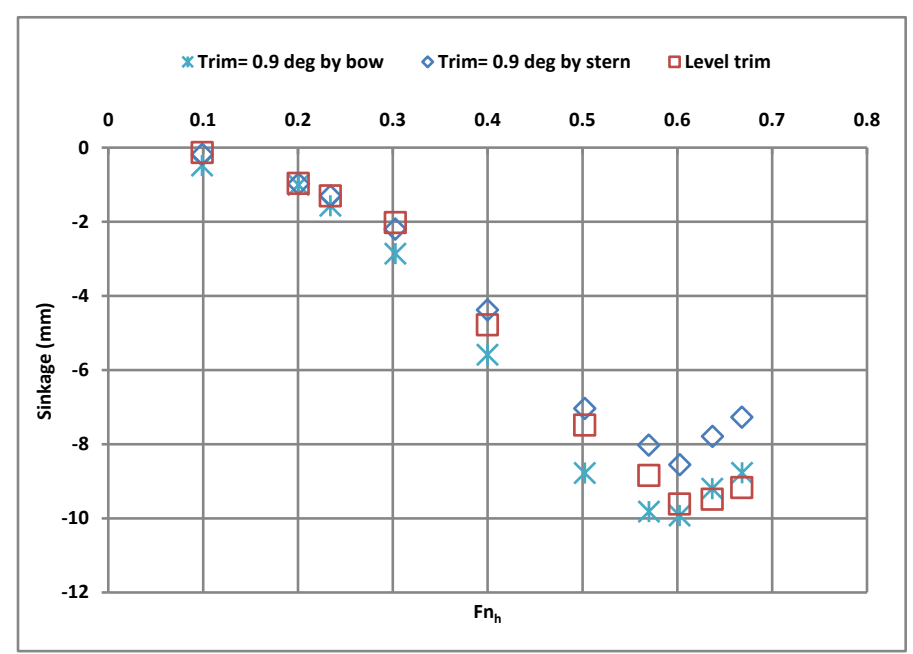

Figure 11: Model sinkage for various trim angle at high and low speed

Figure 11 illustrates model sinkage variations versus trim at 0.23 and 0.67 depth Froude numbers. It can be noticed that for high depth Froude number significant decrease in model sinkage when model was trimmed by stern $(15.6 \%$ for 0.3 degree and $26 \%$ for 0.9 degree), compared to level trim condition. On the other side, model sinkage decreases by $4.5 \%$ for 0.9 degree and $8.5 \%$ for 0.3 degree when model was trimmed by bow. Furthermore, very small increase in model sinkage at slow speed when the model is trimmed by bow.

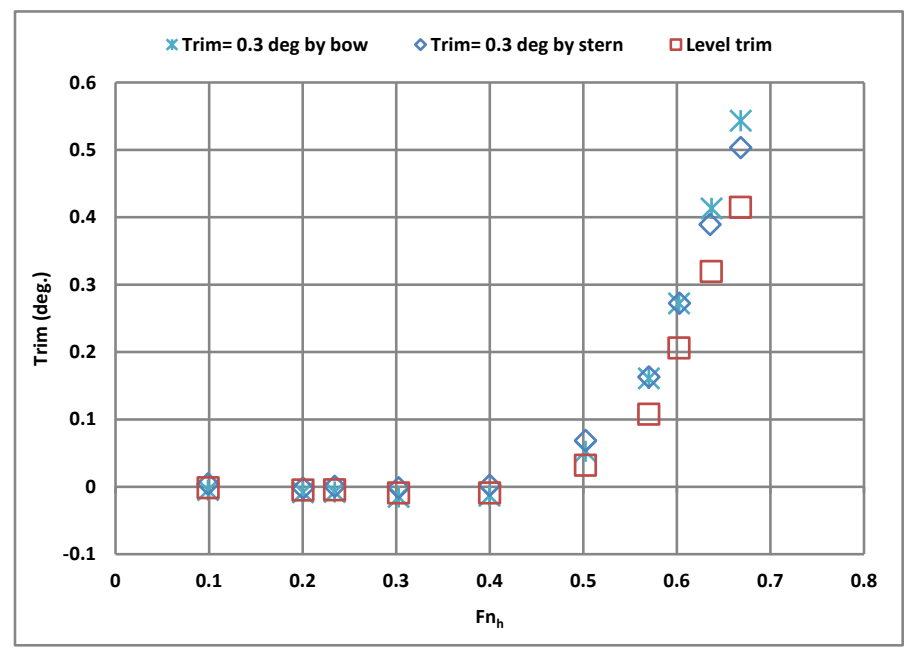

Figure 12: Trim deg. change for the two trim conditions at $0.3 \mathrm{deg}$. and level trim

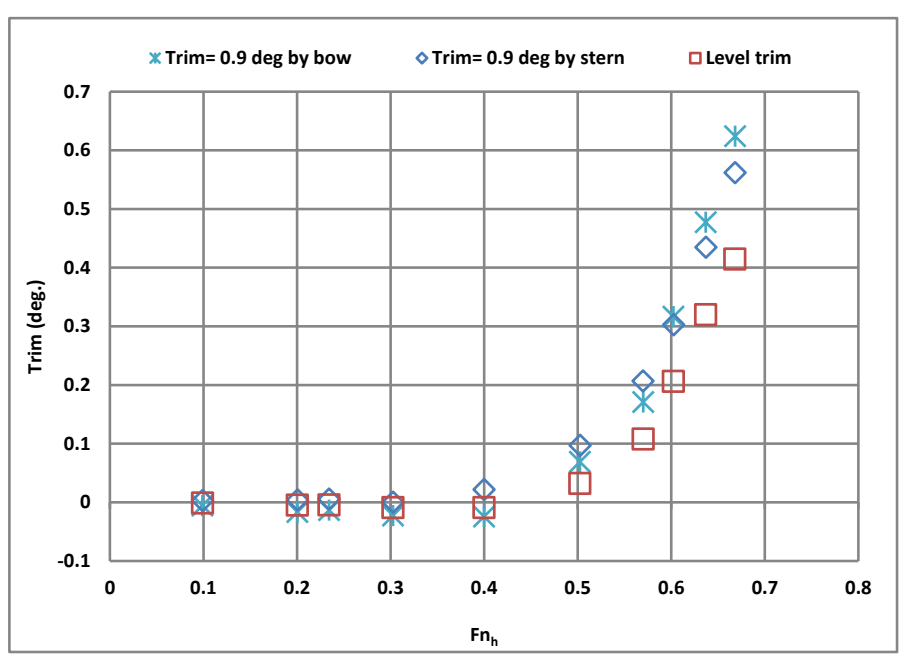

Figure 13: Trim deg. change for the two trim conditions at $0.9 \mathrm{deg}$. and level trim

Figure 12 and 13 display the change in the model trim angles against depth Froude number for three different model initial trimmed conditions. It can be observed that, no significant change in trim values for depth Froude Number range up to 0.4. In contrast, at Froude Numbers greater than 0.4, the ship trim angle tends to increase by stern for all values of model initially trimmed conditions. Level trim angle gave the optimum trim degree for high speed, while 0.9 degree by bow initially condition the largest trim degree value by stern.

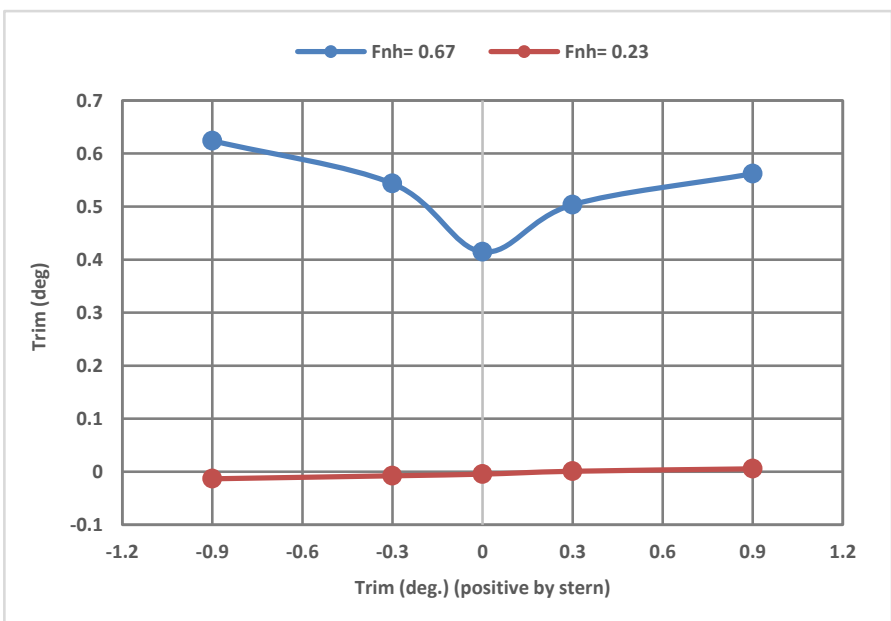

Figure 14: The change in model trim degree for various trim angle at high and low speed.

Figure 14 illustrates the change in model trim angle variations versus trim angle initial condition by bow and by stern at 0.23 and 0.67 depth Froude number respectively. It can be 
noticed that for high depth Froude number significant increase in model trim by stern when model was trimmed by stern in initial condition by $33.5 \%$ for 0.9 degree and $23.6 \%$ for 0.3 degree, compared to level trim condition. On the other side, model trim by stern increased by $26 \%$ for 0.9 degree and $17.6 \%$ Figure 17: Blockage ratio effect on model trim angle 1 initial del trim angle at slow speed when model trimmed by bow and stern.

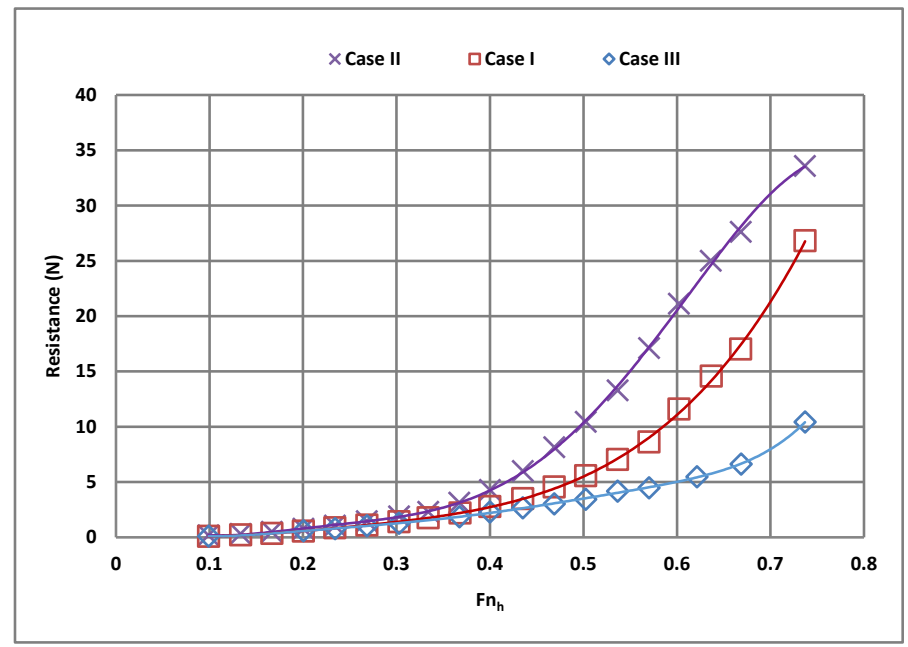

Figure 15: Blockage ratio effect on model total resistance

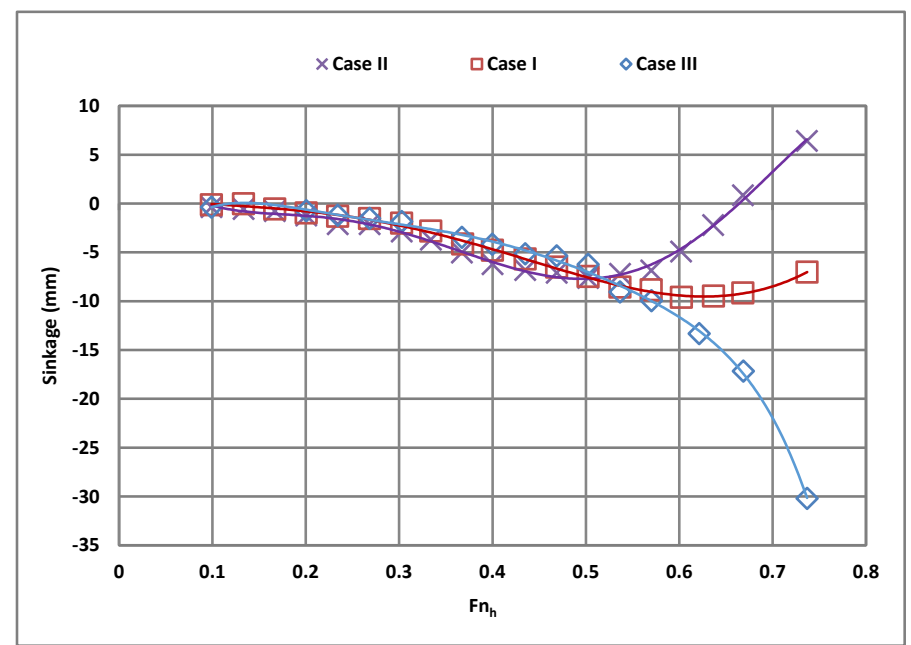

Figure 16: Blockage ratio effect on model sinkage

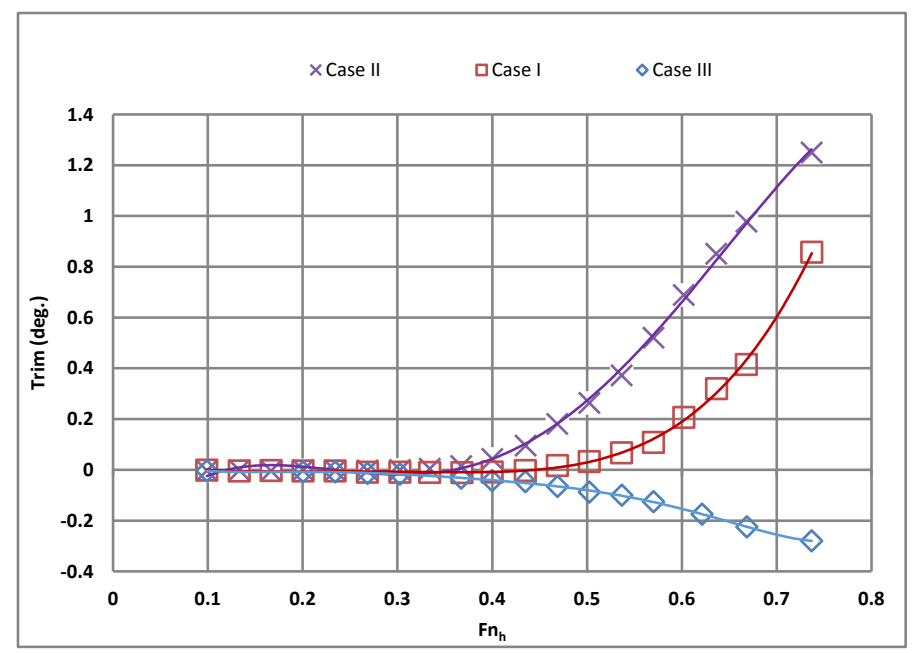

Figures 15, 16 and 17 illustrate the blockage ratio effect on model total resistance and squat. It is clearly noted that, in Case I and Case II model behaviour change after 0.4 depth Froude number due to the combined effect of depth and width change blockage ratio.

As a result, at high ship speed the velocity of return flow around the ship section cannot increase further and a pressure wave will be induced in front of the ship model due to accumulated water in the region (Lataire ) [9] (see to Figure 14). Furthermore, as per Bernoulli's principle, the velocity at ship model stern decreases and accordingly the pressure increases. Albeit, the pressure force acting on the bow will be stronger than on the stern. So, this explains the reason behind getting high aft trim at that low under keel value. On the other hand, the force acting on the ship model stern at subcritical speeds still not strong enough to create net force at the bow to decrease the sinkage of the model. However, once model is run at critical speed the speed under the keel will became higher and will induce induced high pressure change at stern which leads to high force effect on the ship model stern. Accordingly, the net force acting on the ship model will increase and the sinkage will start to decrease, or remains constant when the blockage ratio exceeds critical value.

To calculate the critical depth Froude numbers for a given blockage ratio (K), using Equation (10) [9].

$\mathrm{Fn}_{\mathrm{h}, \mathrm{crit}}=\sin \left(2 \sin \left(\frac{\arcsin (1-\mathrm{K})}{3}\right)\right)^{\frac{3}{2}}$

For Case 1 the blockage ratio $\mathrm{K}=0.067$, the critical speed will occur at $\mathrm{Fn}_{\mathrm{h}}=0.689$ and it clearly noticed in Figure 16 that sinkage starts to decrease and model tends to go up.

Furthermore, for Case 2 the blockage ratio $\mathrm{K}=0.214$, the critical speed will occur at $\mathrm{Fn}_{\mathrm{h}}=0.457$ and it also clearly noticed in Figure 16 that sinkage starts to decrease and model tends go up.

On the contrary, for Case 3 the blockage ratio $\mathrm{K}=0.042$, (very small) the critical speed will occur at $\mathrm{Fn}_{\mathrm{h}}=0.753$, so this explains the reason why sinkage in Figure 16 for Case 3 keeps increasing while the model goes down.

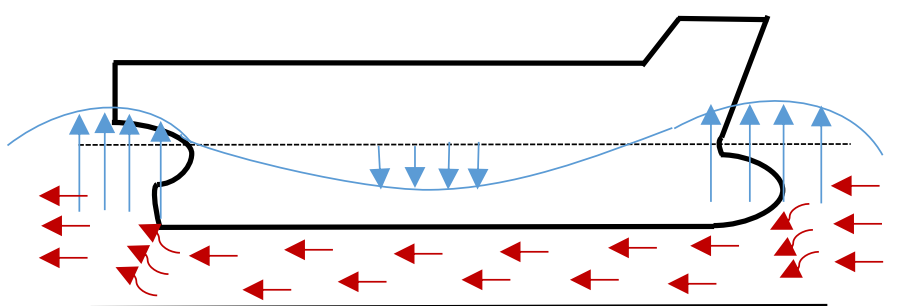

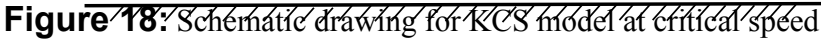




\section{CONCLUSION}

In this study, a series of experimental tests has been carried out for Kriso Container Ship (KCS) model hull focussing on trim optimization. Furthermore, the influence of trim on ship total resistance, sinkage and trim were investigated in shallow water and width restricted channel.

It was observed that no significant impacts on KCS model total resistance, sinkage and trim in all cases studied when the model is sailing at slow speeds were recorded over the depth Froude Number range up to 0.4 .

It was also observed that level trim resulted in lowest resistance for high speeds. Albeit, there is less ship total resistance for the trim by stern case than for trim by bow case. Trim by bow recorded higher ship total resistance for all speeds.

On the other side, it can be noticed that for high depth Froude numbers model sinkage was significantly decreased when model was trimmed by stern, compared to level condition and trimmed by bow condition. Moreover the level trim condition recorded the higher sinkage at high speed.

Finally, it is important to consider the effect of both shallow and restricted water either separately or combined on the ship's sinkage, trim and resistance.

\section{ACKNOWLEDGEMENTS}

The results were obtained conducted at the Kelvin Hydrodynamics Lab at the University of Strathclyde.

\section{REFERENCES}

[1] Larsson, L., Raven, H. C., Paulling, J. R. (2010). The Principles of Naval Architecture Series, Ship Resistance and Flow, Jersey City, New Jersey, The Society of Naval Architects and Marine Engineers.

[2] Lataire, E., Delefortrie, G., Vantorre, M., (2016). Impact of Banks on Ship Squat. 4th MASHCON, Hamburg. DOI: 10.18451/978-3-939230-38-0_15.

[3] Terziev, M., Tezdogan, T., Oguz, E., Gourlay, T., Demirel,Y., K., Incecik, A., (2018) Numerical investigation of the behaviour and performance of ship advancing through restricted shallow waters, Journal of Fluids and Structures, Volume 76 pages 185215.

[4] Constantine, T. (1961), The behaviour of ships moving in restricted waterways. Proceedings of the Institution of Civil Engineers, E-ISSN 1753-7789, Volume 19 Issue 4, AUGUST 1961, pp. 549-562.

[5] Tuck, E.O. (1966), Shallow-water flows past slender bodies. Journal of Fluid Mechanics, Volume 26, Issue 1, September 1966, pp. 81-95.

[6] Millward, A. (1996), A Review of the Prediction of Squat in Shallow Water. The Journal of Navigation, Volume 49, Issue 1 January 1996, pp. 77-88.
[7] Gourlay, T. (2008) Slender-body methods for predicting ship squat. Ocean Eng 35(2):191-200

[8] Delefortrie, G., Vantorre, M., Eloot, K., Vewilligen, J., Lataire, E.. (2010), Squat prediction in muddy navigation areas. Ocean Engineering. Volume 37, Issue 16, November 2010, Pages 1464-1476.

[9] Lataire, E., Vantorre, M., Deleortrie, G. (2012), A prediction method for squat in restricted and rectangular fairways. Ocean Engineering 55 (2012)71-80.

[10] Shivachev, E., Khorasanchi, M., Day, A., H., (2017) Trim Influence on Kriso Container Ship (KCS); An Experimental and Numerical Study.36th International Conference on Ocean, Offshore and Arctic Engineering OMAE, Trondheim, Norway.

[11] Sherbaz, S., Duan, W., (2014). Ship Trim Optimization: Assessment of Influence of Trim on Resistance of MOERI Container Ship. The Scientific World Journal, Volume 2014, Article ID 603695, 6 pages

[12] GUM, I., 2008. Guide to the expression of uncertainty in measurement, (1995), with supplement 1, evaluation of measurement data, jcgm 101: 2008. Organization for Standardization, Geneva, Switzerland.

[13] ITTC, 2017. Uncertainty analysis instrument calibration, in: ITTC procedure 7.5-01-03-01. 